\title{
MODEL MATEMATIKA MIZANUL AMAL: KALKULASI PAHALA DAN DOSA DARI AMAL PERBUATAN SEORANG MUSLIM
}

\author{
Muhammad Wakhid Musthofa \\ Program Studi Matematika, UIN Sunan Kalijaga Yogyakarta \\ muhammad.musthofa@uin-suka.ac.id. \\ Diterima 30-07-2020 | Direview 30-08-2020 | Diterbitkan 15-12-2020
}

\begin{abstract}
:
Doing deeds is the essence of creation of human on the earth, and mankind will be placed in the hereafter based on the deeds. Miranul amal is the scales of human performance, in which all of the rewards and the sins which he has done. This paper presents a mathematical modelling from the calculation of rewards and sins as the replies of the deeds he does. Through the model, it will be obtained an overview of the accumulation of rewards and sins belonging to a muslim. Thus the resulting mathematical model is expected to push a muslim to carefully and wisely in determining the deeds that will do.
\end{abstract}

Keywords: mathematical modelling, deeds, rewards and sins.

\begin{abstract}
Abstrak
Beramal adalah esensi dari diciptakannya manusia di muka bumi dan manusia akan ditempatkan di akbirat berdasarkan amal yang dilakukannya. Mizanul amal adalah timbangan amal seorang manusia, yang di dalamnya terhimpun pabala dan dosa yang telah dilakukannya. Makalah ini menyajikan rumusan matematika (model matematika) dari kalkulasi pahala dan dosa sebagai balasan dari amal perbuatan yang ia lakukan. Melalui model yang disusun akan didapatkan gambaran akumulasi dari pabala dan dosa yang dimiliki seorang muslim. Dengan demikian model matematika yang dihasilkan diharapkan dapat mendorong seorang muslim untuk cermat dan bijak dalam menentukan amal perbuatan yang akan dilakukannya.
\end{abstract}

Kata Kunci: model matematika, amal perbuatan, pahala dan dosa.

\section{Pendahuluan}

Amal adalah perwujudan dari sesuatu yang menjadi harapan bagi jiwa manusia, baik berupa niat di hati, ucapan dengan lisan maupun perlikaku dengan anggota badan. Secara umum amal perbuatan manusia terbagi menjadi dua, yaitu amal baik dan amal buruk. Disebut baik jika harapan jiwa manusia 
tersebut dicintai dan diridhai oleh Allah swt, dan disebut buruk jika sebaliknya ${ }^{1}$.

Manusia sebagai makhluk yang mukallaf di dunia ini mempunyai kewajiban untuk beramal baik dan meninggalkan seluruh amal buruk. Terhadap pelaksanaan kewajiban tersebut Allah menjanjikan balasan pahala dan dosa bagi manusia. Pahala adalah balasan kebaikan dari Allah atas segala amal baik yang dilakukan oleh manusia. Sebaliknya, dosa balasan keburukan dari Allah atas semua amal buruk yang dilakukan oleh manusia di dunia ini.

Meskipun pada hakikatnya seorang muslim memahami apa yang seharusnya ia lakukan agar ia mendapatkan pahala dari Allah swt dan terhindar dari dosa, namun realita menunjukkan banyak muslim yang lalai akan hal tersebut. Hal ini salah satunya dikarenakan dorongan nafsu dari dalam jiwa manusia dan godaan syetan dari aspek eksternalnya. Mereka tenggelam dan disibukkan dengan amal-amal yang berujung dosa dan melalaikan dari mengejar pahala yang akan menyelamatkan kehidupan akhiratnya. Sehingga diperlukan pengingat dan nasehat/motivasi agar seorang muslim senantiasa berada dalam amal sumber pahala yang akan meningkatkan keimanan dan ketaqwaannya.

Model matematika mizanul amal adalah rumusan/persamaan matematika yang menyajikan perhitungan pahala dan dosa yang akan diperoleh dari seluruh amal perbuatan yang dilakukan seorang muslim. Pembentukan model ini diharapkan dapat berfungsi sebagai pengingat bagi nasehat/motivasi seorang muslim agar tetap giat dan konsisten dalam beramal baik dan tegar dalam meninggalkan amal buruk. Melalui model ini seorang muslim dapat melihat bahwa pahala jauh lebih mudah dan lebih banyak untuk didapatkan daripada dosa.

Sejauh pengetahuan penulis, hingga saat ini penelitian tentang merumuskan amal perbuatan manusia dalam bentuk model matematika belum pernah dilakukan oleh peneliti manapun, baik di dalam maupun di luar negeri. Sehingga posisi artikel ini adalah mengawali pembahasan dalam tema tersebut. Penelitian tentang pahala dan dosa pernah dilakukan oleh $\mathrm{Alkaf}^{2}$, namun fokusnya tentang keterkaitan antara pahala dan dosa dengan etos kerja manusia. Demikian juga Madani ${ }^{3}$ membahas status hukum amal perbuatan manusia,

\footnotetext{
${ }^{1}$ al-Kahlani, Subul As-Salam.

${ }^{2}$ Alkaf, "Pemahaman Terhadap Konsep Pahala Dan Dosa Serta Hubungannya Dengan Etos Kerja Dosen Dan Pegawai Fakultas Ushuluddin Dan Pemikiran Islam IAIN Raden Fatah Palembang."

${ }^{3}$ Madani, "Keterkaitan Status Hukum Amal Saleh Dan Surga Dalam Perspektif AlQur'an.”
} 
namun lebih dikaitkan dengan balasan surga. Pada posisi ini, penelitian tentang kalkulasi pahala dan dosa dari amal perbuatan manusia belum pernah diteliti oleh peneliti manapun.

Penyajian balasan pahala dan dosa dari amal perbuatan manusia dengan menggunakan pemodelan matematika memiliki beberapa keunggulan. Diantaranya adalah dikarenakan kalkulasi pahala dan dosa direpresentasikan dalam bentuk persamaan matematika, maka dapat dilakukan simulasi dan studi kasus pada seorang muslim tentang perkiraan banyaknya pahala dan dosa yang akan didapat dari semua amal yang dilakukannya tanpa resiko mendapat dosa sungguhan dari Allah swt. Hal ini dikarenakan simulasi tersebut dilakukan di atas kertas dan dengan program komputer, bukan secara langsung dilakukan oleh yang bersangkutan. Lebih lanjut, melalui model matematika seorang muslim akan memiliki perkiraan dengan tingkat presisi yang sangat tinggi mengenai jumlah pahala dan dosa yang akan didapat dari amal perbuatannya.

Artikel ini disajikan dengan urutan sebagai berikut. Setelah pendahuluan, bagian kedua dari artikel ini menjelaskan tentang bagaimana pahala dan dosa ditetapkan terhadap seluruh amal perbuatan manusia, berdasarkan informasi dari Al Qur'an dan Al Hadits. Berdasarkan hal tersebut bagian ketiga artikel ini menjelaskan penyusunan model matematika amal perbuatan manusia dengan berpedoman pada alur pemodelan matematika dan memanfaatkan penetapan pahala dan dosa pada bagian sebelumnya. Bagian terakhir artikel ini akan menyajikan kesimpulan dari pembahasan yang disajikan dan disertai dengan masalah terbuka yang ditawarkan bagi peneliti selanjutnya.

\section{Metode}

Penelitian ini menyajikan rumusan matematika (model matematika) dari kalkulasi pahala dan dosa sebagai balasan dari amal perbuatan yang ia lakukan. Melalui model yang disusun akan didapatkan gambaran akumulasi dari pahala dan dosa yang dimiliki seorang muslim. fokusnya tentang keterkaitan antara pahala dan dosa dengan etos kerja manusia kalkulasi pahala dan dosa direpresentasikan dalam bentuk persamaan matematika, maka dapat dilakukan simulasi dan studi kasus pada seorang muslim tentang perkiraan banyaknya pahala dan dosa yang akan didapat dari semua amal yang dilakukannya tanpa resiko mendapat dosa sungguhan dari Allah swt. Dengan demikian model matematika yang dihasilkan diharapkan dapat mendorong seorang muslim untuk cermat dan bijak dalam menentukan amal perbuatan yang akan dilakukannya 


\section{Pembahasan}

\section{Penetapan Pahala dan Dosa dari Perbuatan Manusia}

Berikut akan dihimpun fakta-fakta tentang penetapan pahala dan dosa dari amal perbuatan seorang muslim berdasarkan informasi dari Al Qur'an dan Al Hadis. Fakta-fakta tersebut akan dicari hubungan dan kesalingterkaitannya yang selanjutnya akan digunakan untuk menyusun meodel matematika mizanul amal.

Fakta 1. Setiap perbuatan akan diberikan pabala/ dosa berdasarkan niat pelakunya.

Hal ini berdasarkan hadis Nabi saw yang diriwayatkan oleh Bukhari dan Muslim ${ }^{4}$ berikut.

عن أمير المؤمنين أبي حقص عمر بن الخطاب رضي الله عنه قال: سمعت رسول الله صلى الله عليه وسلم يقول: " إنما الأعمال بالنيات و إنما لكل امرىء ما لنان النوى .فمن كانت هجرته إلى الله ورسوله

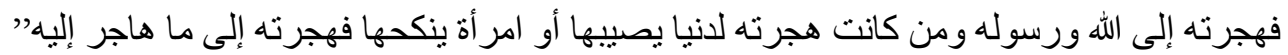

Dari Amirul Mukminin Abu Hafs Umar bin Khoththtoob Rodhiyaallahu 'anhu ia telah berkata: Saya pernah mendengar Rosulullah saw bersabda: "Sesungguhnya amal perbuatan tergantung kepada niyatnya, dan bagi seseorang tergantung apa yang ia niyatkan. Maka barangsiapa yang hijrahnya kepada Allah dan Rosulnya (mencari keridhoannya) maka hijrahnya itu kepada Allah dan Rosulnya (keridhoannya). Dan barangsiapa yang hijrahnya untuk mendapatkan dunia atau untuk menikahi wanita maka hijrahnya itu tertuju kepada yang dihijrahkan."

Fakta 2. Seorang muslim yang telab berniat berbuat baik maka ia telah mendapatkan pahala dari Allah. Namun, jike ia berniat melanggar aturan Allab maka selagi belum dilaksanakan ia tidak akan mendapatkan dosa. Babkan jika ia bertaubat dari niatnya untuk melanggar aturan Allah maka ia akan mendapatkan pabala.

Rasulullah saw bersabda dalam hadis yang diriwayatkan Imam Bukhari dan Muslim

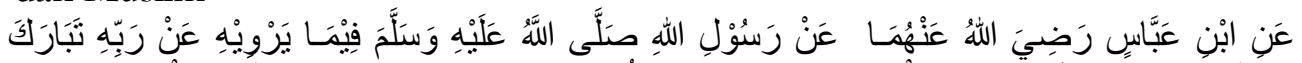

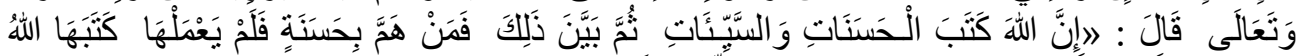

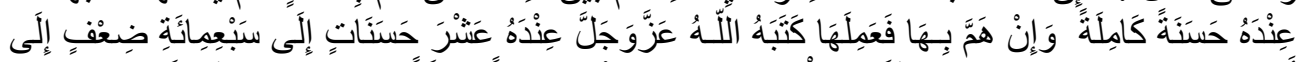

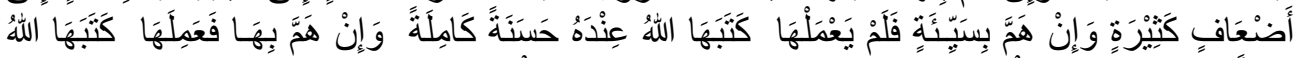

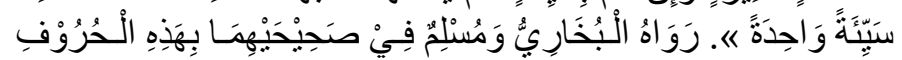

Dari Ibnu 'Abbâs Radhiyallahu anhu dari Nabi saw tentang hadits yang

${ }^{4}$ Panduan Ilmu Dan Hikmah.

${ }^{5}$ al-Bukhari, Shahih Al-Bukhari. 
beliau riwayatkan dari Rabb-nya Azza wa Jalla. Nabi Shallallahu 'alaihi wa sallam bersabda, "Sesungguhnya Allâh menulis kebaikan-kebaikan dan kesalahan-kesalahan kemudian menjelaskannya. Barangsiapa berniat melakukan kebaikan namun dia tidak (jadi) melakukannya, Allâh tetap menuliskanya sebagai satu kebaikan sempurna di sisi-Nya. Jika ia berniat berbuat kebaikan kemudian mengerjakannya, maka Allâh menulisnya di sisi-Nya sebagai sepuluh kebaikan hingga tujuh ratus kali lipat sampai kelipatan yang banyak. Barangsiapa berniat berbuat buruk namun dia tidak jadi melakukannya, maka Allâh menulisnya di sisi-Nya sebagai satu kebaikan yang sempurna. Dan barangsiapa berniat berbuat kesalahan kemudian mengerjakannya, maka Allâh menuliskannya sebagai satu kesalahan.” (HR. al-Bukhâri dan Muslim)

Fakta 3. Allah akan melipatgandakan pahala yang dari amal baik yang dilakukan seorang muslim. Jumlah pelipatgandaan pahala tersebut merupakan bak mutlak. Allah swt. Tetapi terhadap amal buruk yang dilakukan Allah Yang Maha Pengasih tidak akan melipatgandakan dosanya.

Firman Allah dalam Q.S. Al An'am: 160

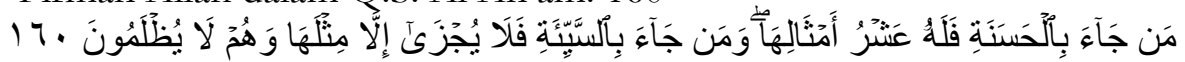

"Barangsiapa membawa amal yang baik, maka baginya (pahala) sepuluh kali lipat amalnya; dan barangsiapa yang membawa perbuatan jahat maka dia tidak diberi pembalasan melainkan seimbang dengan kejahatannya, sedang mereka sedikitpun tidak dianiaya (dirugikan)".

Demikian juga firman Allah dalam Q.S. Al Baqoroh: 261

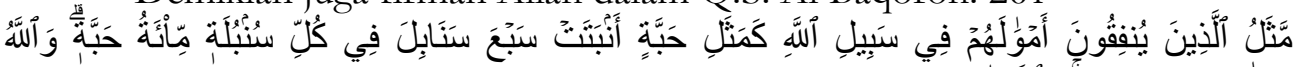

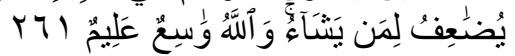

"Perumpamaan (nafkah yang dikeluarkan oleh) orang-orang yang menafkahkan hartanya di jalan Allah adalah serupa dengan sebutir benih yang menumbuhkan tujuh bulir, pada tiap-tiap bulir seratus biji. Allah melipat gandakan (ganjaran) bagi siapa yang Dia kehendaki. Dan Allah Maha Luas (karunia-Nya) lagi Maha Mengetahui”.

Fakta 4. Pahala dari amal ibadah mahdhoh ditentukan berdasarkan tingkat keikhlasan dan kualitas amalnya, juga dari kesempurnaan pemenuban syarat dan rukunnya.

Berkaitan dengan ibadah puasa misalnya, Rasulullah saw bersabda dalam hadits yang diriwayatkan Imam Ahmad ${ }^{6}$.

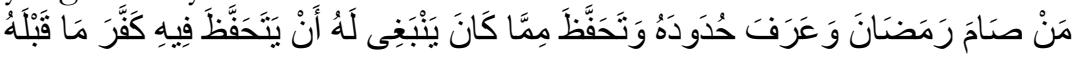

"Barangsiapa berpuasa pada bulan Ramadan dan mengetahui batasbatasnya, dan ia menjaga diri dari segala apa yang patut dijaga, dihapuskanlah

6 'Ibn Hambal, Musnad Al-Imam Ahmad Bin Hanbal. 
dosanya yang sebelumnya".

Hal ini menandakan bahwa ibadah puasa harus disertai dengan kesempurnaan pemenuhan syarat dan rukunnya. Jika syarat dan rukunnya tidak dipenuhi maka puasanya menjadi tidak berpahala. Demikian juga dalam ibadah sholat Rasulullah saw bersabda dalam hadis yang diriwayatkan Abu Dawud ${ }^{7}$.

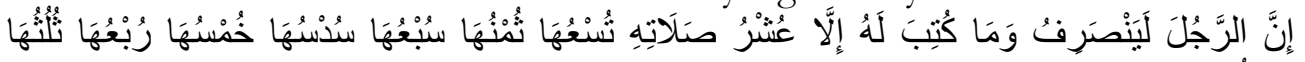

"Sesungguhnya seseorang selesai (dari shalat) dan tidaklah ditulis (pahala) baginya, kecuali sepersepuluh shalatnya, sepersembilannya, seperdelapannya, sepertujuhnya, seperenamnya, seperlimanya, seperempatnya, sepertiganya, setengahya".

Fakta 5. Seorang muslim yang mengajak orang lain untuk berbuat baik maka dia akan mendapatkan pahala perbuatan baiknya beserta dengan pabala orang yang mengikuti perbuatan baiknya tampa orang tersebut dikurangi pabalanya. Hal yang sama juga berlaku jike seorang muslim mengajak orang lain untuk. berbuat dosa.

Rasulullah saw bersabda dalam hadis yang diriwayatkan Imam Muslim ${ }^{8}$

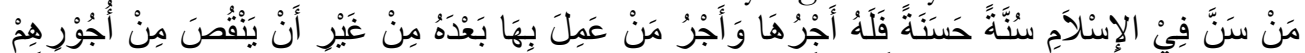

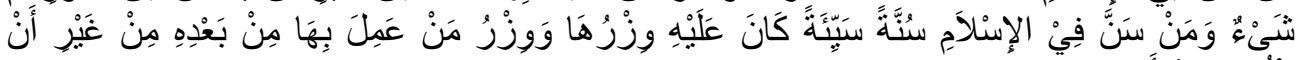

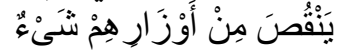

"Barang siapa merintis (memulai) dalam agama Islam sunnah (perbuatan) yang baik maka baginya pahala dari perbuatannya tersebut, dan pahala dari orang yang melakukannya (mengikutinya) setelahnya, tanpa berkurang sedikitpun dari pahala mereka. Dan barang siapa merintis dalam Islam sunnah yang buruk maka baginya dosa dari perbuatannya tersebut, dan dosa dari orang yang melakukannya (mengikutinya) setelahnya tanpa berkurang dari dosa-dosa mereka sedikitpun". (HR. Muslim)

Fakta 6. Jika seorang muslim yang berdosa bertaubat maka Allah akan menghapus dosanya. Majah $^{9}$

Rasulullah saw bersabda dalam hadis yang diriwayatkan Imam Ibnu “النائب من الأنب كمن لا ذنب له”

"Orang yang bertaubat dari perbuatan dosa seperti orang yang tidak memiliki dosa". (HR. Ibnu Majah)

Fakta 7. Perbuatan syirik akbar, yaitu menyekutukan Allab dengan sesembahan selain-

\footnotetext{
${ }^{7}$ Sunan Abi Daud Juz II.

${ }^{8}$ Sahih Muslim.

${ }^{9}$ Abi Abdullah bin Muhammad, Sunan Ibnu Majah.
} 
Nya, akan membatalkan seluruh pabala seorang muslim.

Firman Allah dalam Q.S. Az Zumar: 65

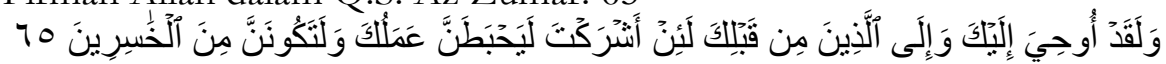

"Dan sesungguhnya telah diwahyukan kepadamu dan kepada (nabinabi) yang sebelummu: Jika kamu mempersekutukan (Tuhan) niscaya akan hapuslah amalmu dan tentulah kamu termasuk orang-orang yang merugi".

\section{Model Matematika Mizanul Amal}

Model matematika adalah persamaan matematika yang menggambarkan suatu obyek yang dimodelkan ${ }^{10}$. Dalam artikel ini akan dirumuskan persamaan matematika yang menggambarkan perhitungan pahala dan dosa yang akan diperoleh dari amal perbuatan seorang muslim. Sehingga persamaan matematika yang dihasilkan disebut sebagai model matematika mizanul amal. Perumusan model ini akan didasarkan pada fakta-fakta yang telah disebutkan pada bagian sebelumnya. Namun sebelumnya, agar diperoleh model yang baik perlu disusun beberapa asumsi ${ }^{11}$ yang terkait dengan obyek pemodelan sebagai berikut.

1. Kalkulasi pahala dan dosa dimodelkan untuk seorang muslim yang mukallaf, yaitu seorang muslim yang secara penuh mendapatkan beban tanggung jawab beribadah kepada Allah swt. Sehingga muslim yang belum baligh, menderita sakit jiwa dan yang kehilangan kesadaran tidak termasuk sebagai obyek yang dimodelkan dalam penelitian ini.

2. Amal perbuatan yang akan dihitung pahala dan dosanya dibatasi pada amal perbuatan yang dijanjikan mendapatkan balasan pahala dengan jumlah tertentu dari Allah swt, berdasarkan informasi dari Al-Qur'an dan AlHadis. Misalnya, pahala shodaqoh akan dilipatgandakan 700 kali lipat $^{12}$. Sedangkan amal perbuatan yang janji balasannya berwujud materi maupun non-materi tidak masuk dalam perhitungan. Misalnya, sholat rowatib 12 rokaat sehari semalam akan mendapatkan satu rumah di surga ${ }^{13}$. Hal ini tidak termasuk yang dimodelkan.

\footnotetext{
${ }^{10}$ Mathematical Models in the Social and Behavioral Sciences.

${ }^{11}$ Pemodelan Matematis.

${ }^{12}$ Ensiklopedi Fiqih Islam Fiqih Sunnah 1, 1.

${ }^{13} 1$.
} 
3. Amal perbuatan yang pahalanya dijanjikan tanpa batas juga tidak masuk dalam obyek pemodelan ini. Diantaranya adalah pahala bagi seorang yang bersabar ${ }^{14}$.

4. Amal perbuatan yang selain dijanjikan pahala juga akan mendapatkan pengampunan dosa maka hanya pahala saja yang akan dihitung. Hal ini dimaksudkan untuk menghindari kompleksitas dalam pemodelan. Contoh amal yang termasuk kategori ini adalah sholat. Selain dijanjikan mendapat pahala, orang yang mendirikan sholat juga akan mendapatkan pengampunan dosa ${ }^{15}$. Maka, hanya pahala saja yang akan dihitung dari amal sholat tersebut.

Setelah asumsi di atas disusun, batasan obyek yang akan dimodelkan menjadi semakin jelas. Pada tahap ini perumusan persamaan matematika yang menggambarkan jumlah pahala dan dosa dari amal perbuatan seorang muslim siap untuk dilakukan. Berikut dipaparkan perumusan model matematika mizanul amal berdasarkan pada fakta-fakta yang telah disusun.

Guna mempermudah penyajian, model mizanul amal dibagi menjadi dua persamaan, yaitu persamaan yang menggambarkan perolehan pahala dan persamaan yang menggambarkan perolehan dosa. Didefinisikan $P$ adalah jumlah pahala yang akan diperoleh seorang muslim dan $D$ adalah jumlah pahala yang akan diperoleh seorang muslim. Berdasarkan Fakta 5 seseorang dapat memperoleh pahala/dosa disebabkan amal pribadi yang dikerjakannya dan dari orang lain yang mengamalkan kebaikan/keburukan karena ajakannya. Dengan demikian didapatkan persamaan

$$
\begin{gathered}
P=P_{p}+P_{o l} \\
D=D_{p}+D_{o l},
\end{gathered}
$$

dengan

$P_{p}=$ jumlah pahala yang diperoleh dari amal pribadi yang dikerjakan,

$P_{o l}=$ jumlah pahala yang diperoleh dari orang lain yang mengamalkan kebaikan karena ajakannya,

$D_{p}=$ jumlah dosa yang diperoleh dari amal pribadi yang dikerjakan, $D_{o l}=$ jumlah dosa yang diperoleh dari orang lain yang mengamalkan keburukan karena ajakannya.

\footnotetext{
${ }^{14}$ Al-Qur'an Dan Terjemahnya.

${ }^{15}$ al Jazairi, Minhajul Muslim, Konsep Hidup Ideal Dalam Islam.
} 
Besarnya $P_{o l}$ akan bergantung pada jumlah orang yang lain yang mengamalkan kebaikan dan jumlah amal kebaikan yang diamalkannya. Hal ini dinyatakan dalam persamaan

$$
P_{o l}=\sum_{i=1}^{n}\left(\sum_{j=1}^{m_{1}} P_{i j}+\sum_{k=1}^{m_{2}} P_{i k}+\ldots+\sum_{l=1}^{m_{3}} P_{i l}\right),
$$

dengan $n, n_{1}, n_{2}, m_{n} \in \mathrm{N}$ dan $P_{i j}$ menyatakan jumlah pahala yang diperoleh dari orang lain ke $i$ yang mengerjakan amal kebaikan ke $j$. Keofisien $n$ menyatakan jumlah orang yang mengamalkan kebaikan atas ajakan yang bersangkutan, sedangkan banyaknya suku dalam Persamaan (3) menunjukkan jumlah amal-amal kebaikan yang dilakukan oleh orang yang mengikuti. Menggunakan logika yang sama bersarnya $D_{o l}$ dapat dinyatakan dengan persamaan

$$
D_{o l}=\sum_{i=1}^{n_{1}}\left(\sum_{j=1}^{n_{2}} D_{i j}+\sum_{k=1}^{n_{3}} D_{i k}+\ldots+\sum_{l=1}^{n_{4}} D_{i l}\right),
$$

dengan $D_{i j}$ menyatakan jumlah dosa yang diperoleh dari orang lain ke $i$ yang mengerjakan amal keburukan ke $j$.

Berdasarkan Fakta 2, pahala yang diperoleh dari amal pribadi yang dikerjakan dapat dibagi menjadi dua, yaitu pahala yang didapat dari amal yang telah dilakukan dan pahala yang didapat dari niat suatu perbuatan baik yang tidak terlaksana. Sehingga didapat persamaan

$$
P_{p}=P_{p a}+P_{p b}
$$

dengan

$P_{p a}=$ jumlah pahala yang didapat dari amal yang telah dilakukan,

$P_{p b}=$ jumlah pahala yang diperoleh dari niat suatu perbuatan baik yang tidak terlaksana.

Besarnya $P_{p b}$ akan bergantung pada besarnya pahala niat dari Allah swt dan kualitas niat tersebut, sehingga $P_{p a}$ dapat dinyatakan dengan persamaan

$$
P_{p b}=\alpha P_{N}
$$

dengan

$\alpha=$ kualitas niat,

$P_{N}=$ pahala niat dari Allah swt. 
Selanjutnya, berdasarkan Fakta 1, 3, dan 4 pahala yang didapat dari amal yang telah dilakukan oleh seseorang akan bergantung kepada kualitas niat, pelipatgandaan pahala oleh Allah swt dan kualitas amal serta kesempurnaan syarat dan rukun perbuatan tersebut. Hal ini secara matematis dapat disajikan dengan persamaan berikut

$$
P_{p a}=\beta \gamma P_{A}
$$

dengan,

$\beta=$ kualitas niat, kualitas amal serta kesempurnaan syarat dan rukun perbuatan,

$\gamma=$ pelipatgandaan pahala oleh Allah swt,

$P_{A}=$ pahala pelaksanaan amal.

Substitusikan Persamaan (6) dan (7) ke dalam Persamaan (5) diperoleh peramaan

$$
P_{p}=\beta \gamma P_{A}+\alpha P_{N}
$$

Selanjutnya substitusikan Persamaan (3) dan (8) diperoleh persamaan

$$
P=\beta \gamma P_{A}+\alpha P_{N}+\sum_{i=1}^{n_{1}}\left(\sum_{j=1}^{n_{2}} P_{i j}+\sum_{k=1}^{n_{3}} P_{i k}+\ldots+\sum_{l=1}^{n_{4}} P_{i l}\right) .
$$

Persamaan (9) mendeskripsikan jumlah pahala yang akan diperoleh seorang muslim dari perbuatan yang dilakukannya.

Berikutnya akan dimodelkan dosa yang diperoleh dari amal pribadi yang dikerjakan. Dosa ini akan bergantung pada kualitas dari perbuatan dosa tersebut dan pilipatgandaan dosa dari Allah swt. Sehingga didapat persamaan

$$
D_{p}=\eta \lambda D_{A}
$$

dengan,

$\eta=$ kualitas perbuatan dosa,

$\lambda=$ pelipatgandaan dosa oleh Allah swt,

$D_{A}=$ dosa perbuatan.

Substitusikan Persamaan (4) dan (10) ke dalam Persamaan (2) diperoleh persamaan

$$
D=\eta \lambda D_{A}+\sum_{i=1}^{n_{1}}\left(\sum_{j=1}^{n_{2}} D_{i j}+\sum_{k=1}^{n_{3}} D_{i k}+\ldots+\sum_{l=1}^{n_{4}} D_{i l}\right)
$$

Berdasarkan Fakta 7 maka dosa akan hilang setelah seseorang bertaubat kepada Allah swt. Hal ini secara matematis dinyatakan dengan 


$$
-\delta T_{D}
$$

dengan,

$\delta=$ kualitas taubat,

$T_{D}=$ Perbuatan dosa yang ditaubatkan kepada Allah swt.

Tambahkan (12) ke dalam Persamaan (11) diperoleh

$$
D=\eta \lambda D_{A}+\sum_{i=1}^{n_{1}}\left(\sum_{j=1}^{n_{2}} D_{i j}+\sum_{k=1}^{n_{3}} D_{i k}+\ldots+\sum_{l=1}^{n_{4}} D_{i l}\right)-\delta T_{D} .
$$

Persamaan (13) menyatakan jumlah dosa yang akan diterima oleh seorang muslim akibat perbuatan yang dilakukan.

Selanjutnya, berdasarkan Fakta 7, perbuatan syirik akbar akan membatalkan seluruh pahala seorang muslim. Berdasarkan hal ini maka Persamaan (9) akan berubah menjadi

$$
P=\left(\beta \gamma P_{A}+\alpha P_{N}+\sum_{i=1}^{n_{1}}\left(\sum_{j=1}^{n_{2}} P_{i j}+\sum_{k=1}^{n_{3}} P_{i k}+\ldots+\sum_{l=1}^{n_{4}} P_{i l}\right)\right) S
$$

Dengan $S$ menyatakan perbuatan syirik akbar yang dilakukan, dan $S$ mengikuti rumus

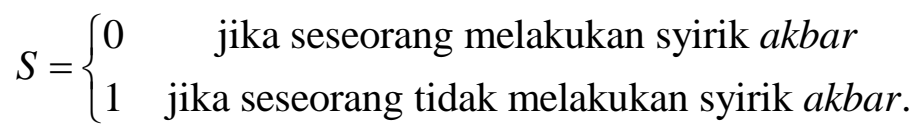

Sistem persamaan $(13,14)$ inilah yang disebut sebagai model matematika mizanul amal. Sistem persamaan tersebut menggambarkan dinamika pahala dan dosa yang diperoleh seorang muslim berdasarkan amal perbuatan yang dilakukannya.

\section{Simpulan}

Melalui penelitian ini dapat disimpulkan bahwa:

1. Rumusan pahala disajikan oleh Persamaan (14) dan rumusan dosa disajikan oleh Persamaan (13). Dari dua persamaan tersebut terlihat bahwa suku pada Persamaan (14) lebih banyak dibandingkan dengan suku pada Persamaan (13)

2. Untuk mendapatkan pahala lebih banyak dari pada jalan yang mengakibatkan dosa, atau ringkasnya peluang untuk mendapatkan pahala lebih banyak dari pada peluang untuk berbuat dosa. Inilah wujud kemurahan dan kasih sayang Allah swt kepada para hambaNya. 


\section{Daftar Pustaka}

Abi Abdullah bin Muhammad. Sunan Ibnu Majah. Dar Al-fikr, n.d.

Abu Dawud. Sunan Abi Daud Juz. II. Beirut: Dar al-Fikr, n.d.

Alkaf, I. "Pemahaman Terhadap Konsep Pahala Dan Dosa Serta

Hubungannya Dengan Etos Kerja Dosen Dan Pegawai Fakultas

Ushuluddin Dan Pemikiran Islam IAIN Raden Fatah Palembang." Intizar 9 (2013).

Bukhari, Al-Imam Abu Abdillah Muhammad bin Ismail al-. Shabih Al-Bukhari.

Beirut Libanon: Dar al-Kutub al-Ilmiyah, 1992.

Dewan Penterjemah al-Qur'an Depag RI. Al-Qur'an Dan Terjemabnya. Medinah Munawwarah: Mujamma' Khadim al-Haramain, $1411 \mathrm{H}$.

'Ibn Hambal, A. Musnad Al-Imam Ahmad Bin Hanbal. Vol. VI. Kairo:

Mu'assasah Qurtubah, n.d.

Jazairi, A. B al. Minhajul Muslim, Konsep Hidup Ideal Dalam Islam. Jakarta: Darul Haq, 2011.

Kahlani, Muhammad bin Ismail al-. Subul As-Salam. Beirut: Dar Al-Fikr, n.d.

Madani, A.M. "Keterkaitan Status Hukum Amal Saleh Dan Surga Dalam

Perspektif Al-Qur'an." Asy-Syir'ah Jurnal Ilmu Syariah Dan Hukum, 2, 48 (2014).

Muslim, Imam Abu Husain. Sabih Muslim. Beirut: Dar al-Kitab al-Ilmiyah, n.d.

Rajab, I. Panduan Ilmu Dan Hikmah. 2002nd ed. Jakarta: Darul Falah, n.d.

Rapoport, A. Mathematical Models in the Social and Behavioral Sciences. 1983rd ed.

New York: John Wiley \& Sons, n.d.

Sabiq, S. Ensiklopedi Fiqih Islam Fiqih Sunnah 1. Yogyakarta: Mardhiyah Press, 2006.

Susanta, B. Pemodelan Matematis. Jakarta: Univeritas Terbuka, 2008. 